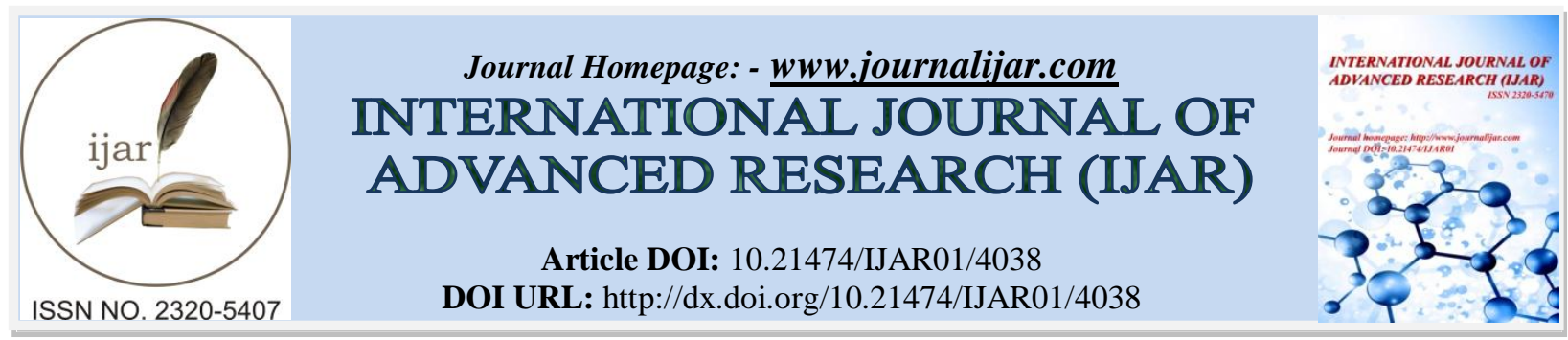

RESEARCH ARTICLE

\title{
CALCIUM HYPOCHLORITE CAUSES ANNIHILATION OF BIO-MOLECULES OF NOSEMA SPORES PURIFIED FROM ANTHERAEA MYLITTA.
}

\section{${ }^{*}$ K. Jena ${ }^{1}$, J. P. Pandey ${ }^{1}$, A. Upadhya ${ }^{2}$, Y. D. Mishra ${ }^{2}$, V. P. Gupta ${ }^{1}$, A. K. Sinha ${ }^{1}$, Ruchi Kumari ${ }^{1}$ and Anshu Priya ${ }^{3}$.}

1. Central Tasar Research \& Training Institute (Central Silk Board, Ministry of Textiles Govt. of India) Piska Nagari, Ranchi-835303, Jharkhand, India.

2. Govt. V.Y.T.PG. Autonomous College, Durg-491001, Chhattisgarh.

3. Vellore Institute of Technology, Vellore, Tamil Nadu-632014, India.

\section{Manuscript Info}

Manuscript History

Received: 15 February 2017

Final Accepted: 19 March 2017

Published: April 2017

Key words:-

Nosema; Calcium Hypochlorite tasar silkworm; bleaching; membrane damage

\begin{abstract}
industry. Sometimes it destroys the growth and development of sericulture, especially in seed and cocoon production sectors. Although the bleaching powder is effective to efficiently act on Nosema spores, but the mechanism was not understood well. Therefore, the present study has been carried out to investigate the mechanism of Calcium Hypochlorite on Nosema spores. Interestingly, higher level of membrane damage, protein and carbohydrate leakages were observed in Nosema spores treated with bleaching powder solution. The inactivation of spores was additionally verified by using mortality test (double color fluorescence stain and scanning electron microscope). In addition, the protein and membrane of spores was disrupted, which resulted in the annihilation of the structure of the spores. Present findings provide new insights into the mechanism of bleaching powder solution on Nosema spores.
\end{abstract}

Copy Right, IJAR, 2017,. All rights reserved.

Nosema spores cause very lethal

disease "Pebrine" to sericulture

\section{Introduction:-}

Pebrine is a common disease in silkworm caused by Nosema Sp., which sometimes destroy the development of tasar culture, especially in seed and cocoon production sectors. A significant cause of disease in tasar culture is due to primary and secondary contamination of Pebrine. Since tropical tasar silkworms rearing is conducted outdoor condition, therefore, very little scope to control the disease in full proof manner. This scenario are more defenceless to various other pathogens too. Among these A. mylitta is very often infected with microsporidia (genus Nosema), which all most affects all stages and ecoraces of silkworm (Jena et al., 2016). Further, silkworm has neither morphological nor behavioural adaptation to escape parasites, and no race of tasar silkworm is completely immune to pebrine diseases. In its host Nosema is considered to cause major health problems characterized by oxidative damages (Jena et al., 2014), reduction of protein level (Madhusudhan et al., 2011), silk gland weight and excretory products (Renuka and Shamitha, 2012) and larval growth (Rath et al., 2003). Generally, healthy and hygienic grainage and rearing operation can reduce the risk of diseases incidence. To overcome major disadvantages associated with formalin based disinfection, bleaching powder was recommended as disinfectant. Chlorine is one of the most commonly used disinfectants and can be applied for the deactivation of most microorganisms and it is

Corresponding Author:- K. Jena.

Address:- Central Tasar Research \& Training Institute (Central Silk Board, Ministry of Textiles Govt. of India) Piska Nagari, Ranchi-835303, Jharkhand, India. 
relatively cheap. It is important from a practical standpoint to investigate the inactivation mechanism of $N$. mylitta spores by bleaching powder solution and elucidate the mechanism involved. This knowledge could be used to develop bleaching as a highly-effective and environmentally-safe chemical for silkworm egg production in judicious manner.

\section{Materials and Methods:- Spore purification:-}

Nosema spores were isolated from diseased pupae of Daba ecoraces. Spores were purified according to lab protocol (Jena et al., 2015, 2016). Samples were homogenized in $0.6 \% \mathrm{~K}_{2} \mathrm{CO}_{3}$, filtered and the filtrate was centrifuged at $3000 \mathrm{rpm}$ for $15 \mathrm{~min}$. Spores were purified on discontinuous sucrose gradient $(25,50$ and $75 \%)$ by centrifugation at $4000 \mathrm{rpm}$ for $10 \mathrm{~min}$. The spores were collected from the sediment and washed in distilled water thrice and stored as stock at $4^{\circ} \mathrm{C}$ in $0.85 \% \mathrm{NaCl}$ until use. They were then suspended in distilled water and counted using haemocytometer.

$\mathbf{P}^{\mathrm{H}}$ and chlorine content estimation:-

$\mathrm{P}^{\mathrm{H}}$ was analysed by $\mathrm{pH}$ meter. Chlorine level in bleaching solution was estimated by thiosulfate titration methods.

\section{Reagent preparation:-}

The staining solution was prepared with $0.02 \%$ of Acridine orange (AO) and $0.013 \%$ of propidium iodide (PI) at a ratio of 3:1. The solution was mixed and preserved at $4^{0} \mathrm{C}$.

\section{Inactivation test of bleaching solution on Nosema spores:-}

Spores were centrifuged at $1000 \mathrm{~g}$ for $5 \mathrm{~min}$. The pellets were then dissolved in $100 \mu \mathrm{l}$ of bleaching solution at different concentrations $(1 \%, 2.5 \%$ and $5 \%)$ for 15 min. Sterile water-treated sample as a negative control, and the sample autoclaved $(30 \mathrm{~min})$ treated as a positive control. Three repetitions were conducted for every treatment. All tests were conducted at room temperature. The glass slides were daubed with spores, dried in the shade, stained with $0.02 \%$ of $\mathrm{AO}$ and $0.013 \%$ of PI (3:1) for $10 \mathrm{~min}$. Fluorescence microscopy was used to observe the spores at excitation of $490 \mathrm{~nm}$ and the Grating filter at $510 \mathrm{~nm}$.

\section{Estimation of protein loss:-}

After treatment, sample was centrifuged and supernatants were collected for estimation of protein loss. Supernatant were treated with $20 \% \mathrm{TCA}$ and stored in ice for $15 \mathrm{~min}$ to complete precipitation. The treated samples were centrifuged and pallets were solubilised in $1 \mathrm{~N} \mathrm{NaOH}$. The protein content was estimated by the Bradford (1976) method using bovine serum albumin as standard.

\section{Detection of the malonaldehyde (MDA):-}

Lipid peroxidation (LPX) level was assayed by measurement of malondialdehyde (MDA), a decomposition product of polyunsaturated fatty acids hydro peroxides were determined by the thiobarbituric acid (TBA) reaction as described by Bar-Or et al. (2001). Briefly, the reaction mixture containing $0.1 \mathrm{~mL}$ of sample, $0.9 \mathrm{~mL}$ of $0.8 \%$ aqueous solution of TBA (in 20\% TCA). Then the mixture was heated at $95^{\circ} \mathrm{C}$ for $60 \mathrm{~min}$ and cooled. The supernatant was read at $532 \mathrm{~nm}$ after removal of any interfering substances by centrifuging at $4000 \mathrm{xg}$ for $10 \mathrm{~min}$. The amount of MDA formed was calculated by using an extinction coefficient of $1.56 \times 105 \mathrm{M}^{-1} \mathrm{~cm}^{-1}$ (Wills 1969), and expressed as nmol MDA $/ 10^{6}$ spores.

\section{FTIR Analysis:-}

Infrared spectra of bleaching treated spores were measured by FTIR Spectroscopy. All the spectra were taken in the spectral range of 4000-450 $\mathrm{cm}^{-1}$ (Outsource: Central Instrumentation Facility Laboratory, BIT Mesra, Ranchi).

\section{Scanning electron Microscopy:-}

Scanning electron microscopy (SEM) of control and bleaching treated spores were measured by SEM. The morphology study was conducted at BIT, Mesra (Outsourced: Central Instrumentation Facility Laboratory, BIT Mesra, Ranchi).

\section{Statistical Analysis:-}

Results were expressed as mean \pm standard deviation (SD). Difference between control and treatment was analyzed by ANOVA. Differences were considered statistically significant when $p<0.05$. 


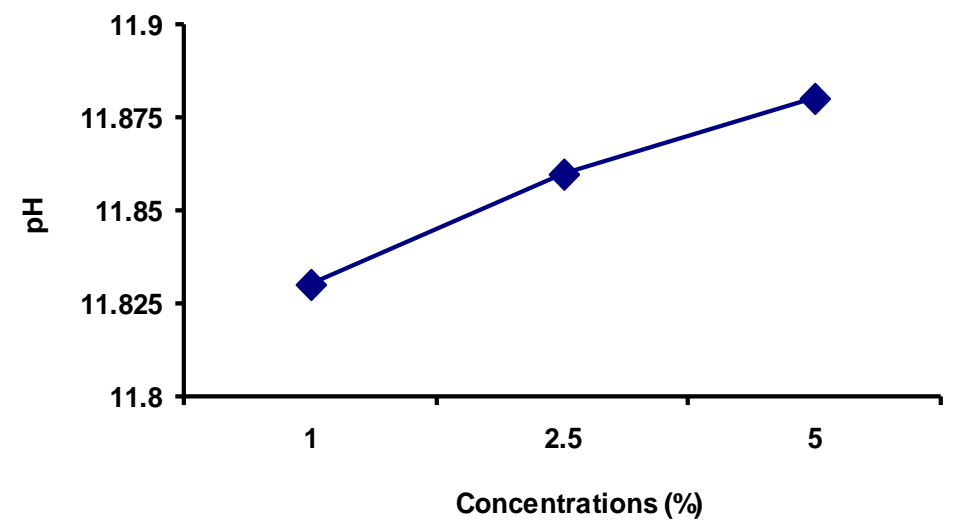

Fig 1:- $\mathrm{P}^{\mathrm{H}}$ of different bleaching solutions

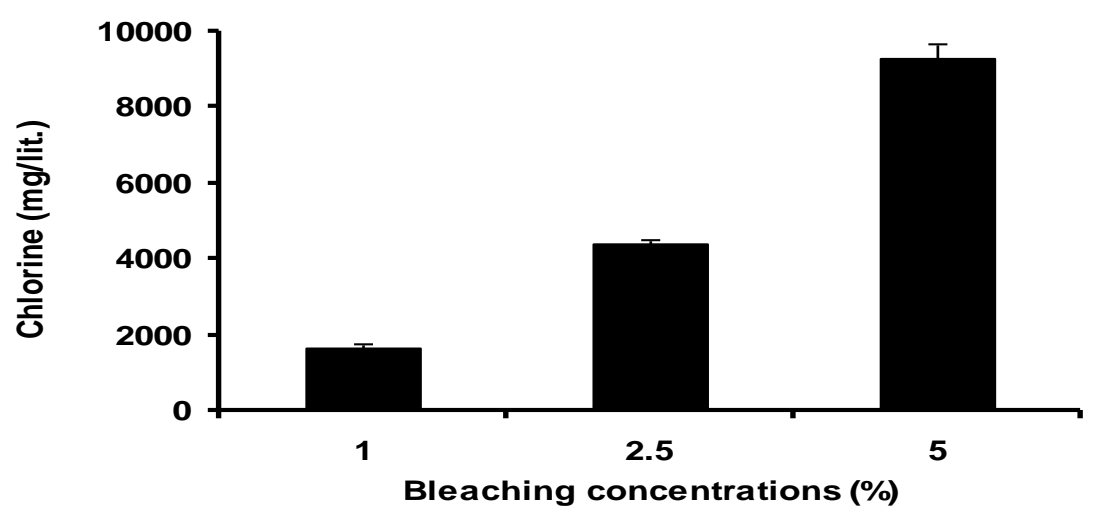

Fig 2:- Amount of chlorine available in respective bleaching solutions.
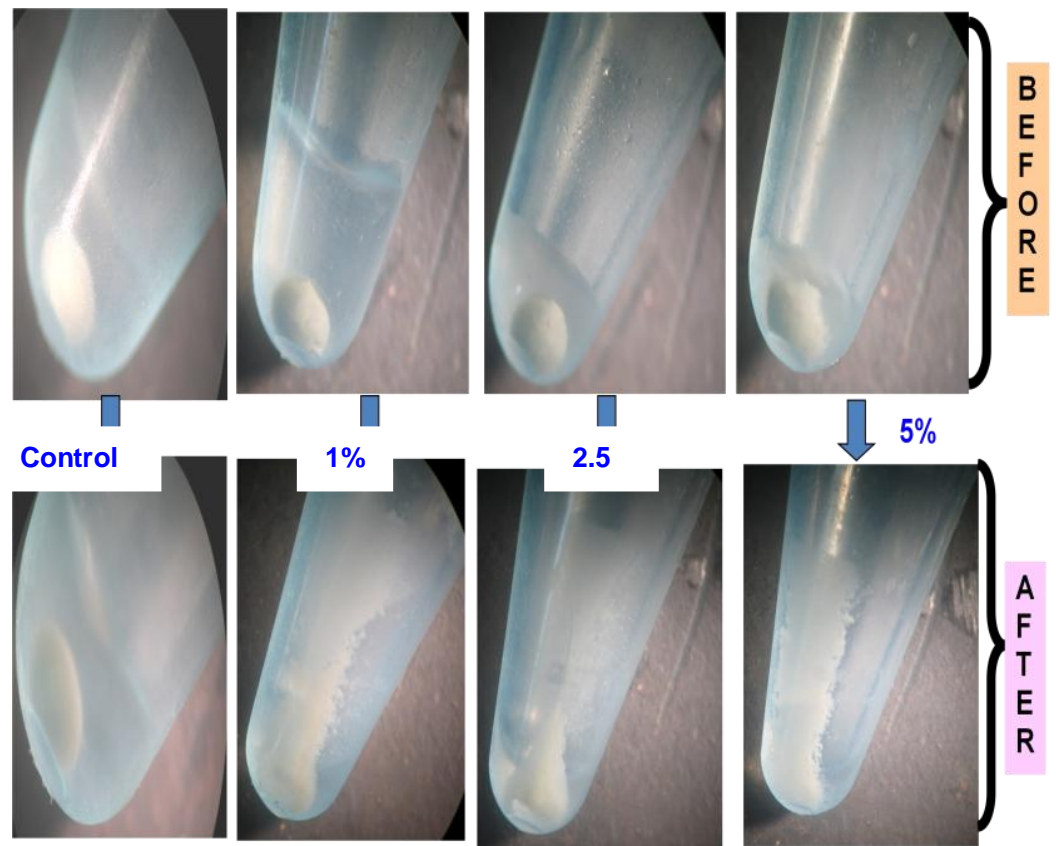

Fig 3:- Degradation of memberanes after bleaching treatment. 

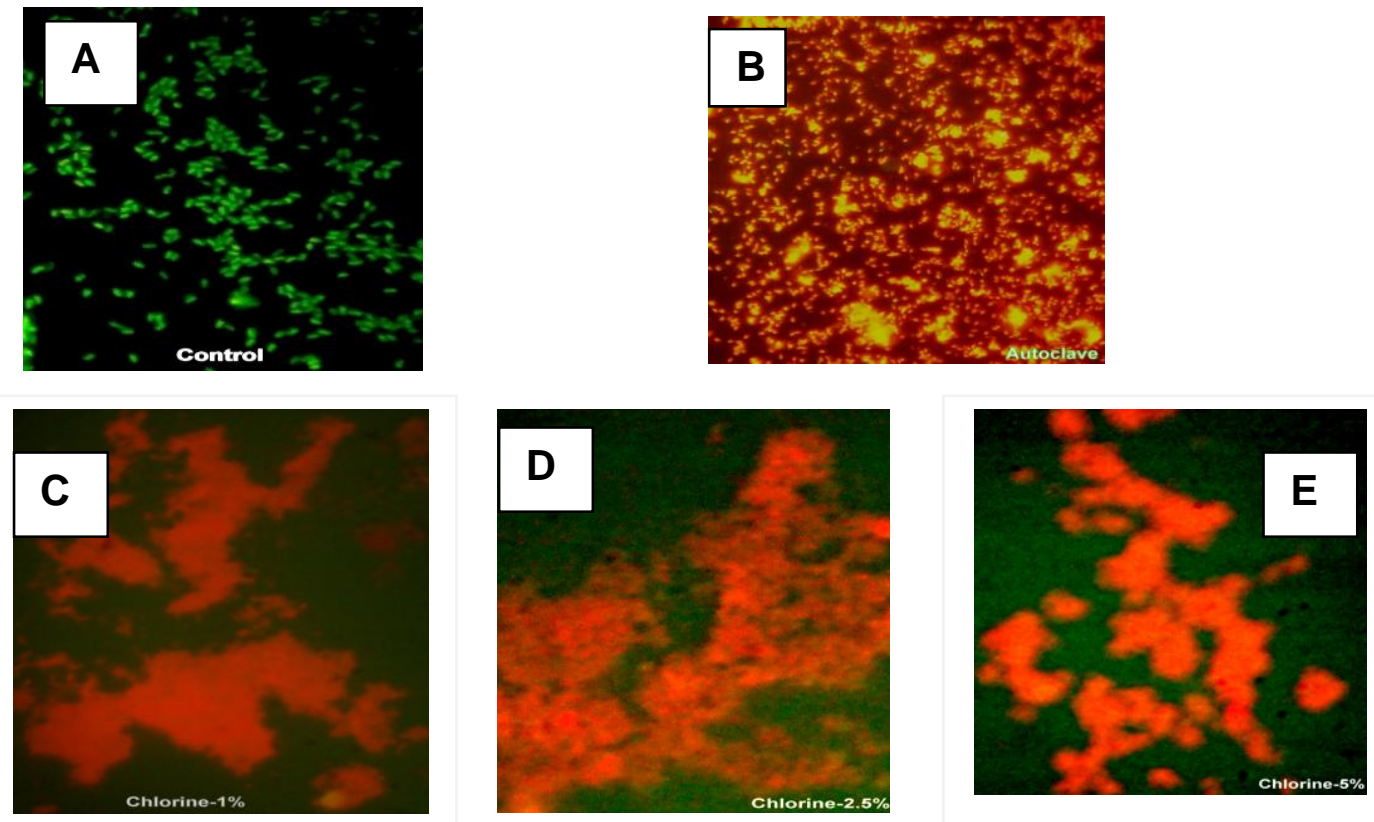

Fig 4:- Mortality of spores after bleaching treatment. (A) Control, (B) Autoclave treated, (C) $1 \%$ bleaching solution treated, (D) $2.5 \%$ bleaching solution treated (E) $5 \%$ bleaching solution treated

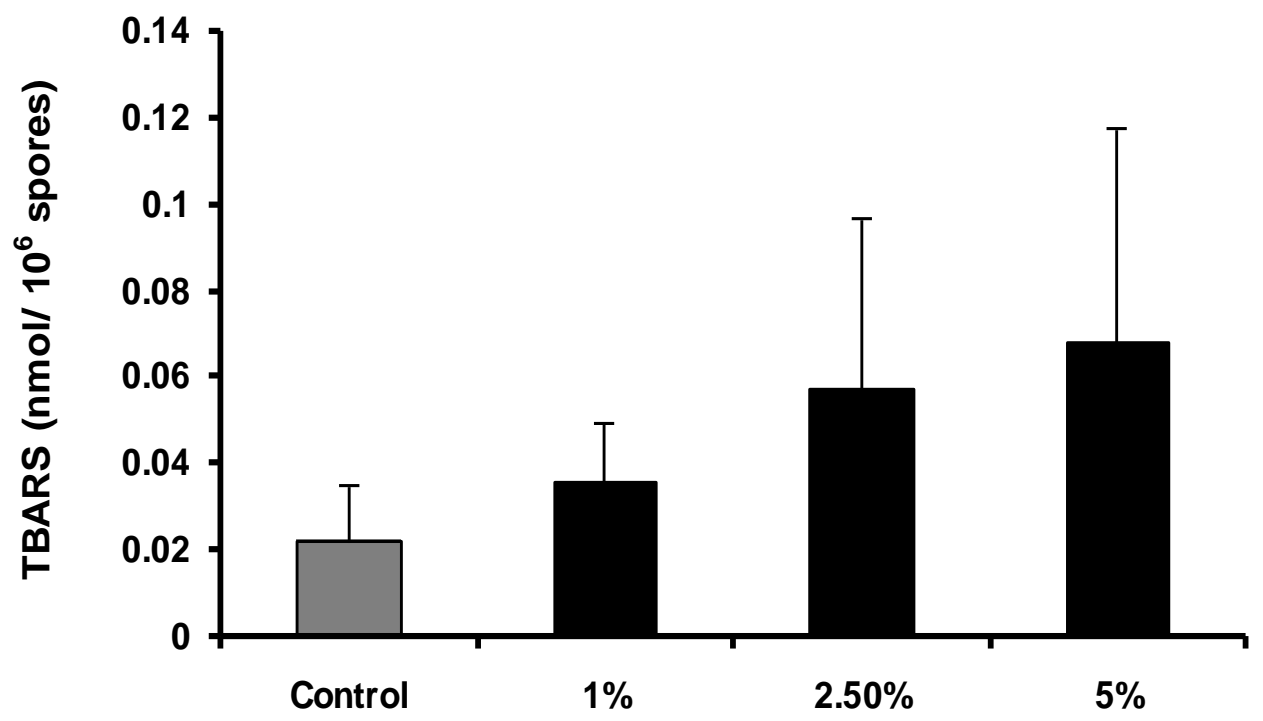

Fig 5:- Effect of bleaching solution on lipid peroxidation. Data expressed as mean $\pm \operatorname{SD}(n=3)$. 

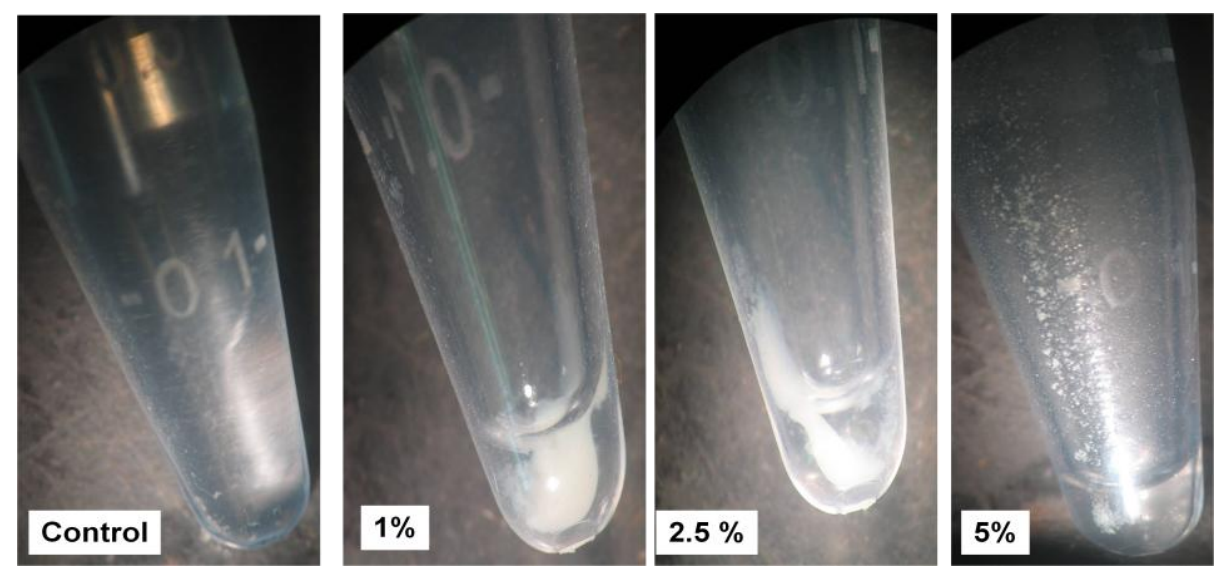

Fig 6:-Visualisation of protein leakage from spores during bleaching treatment.

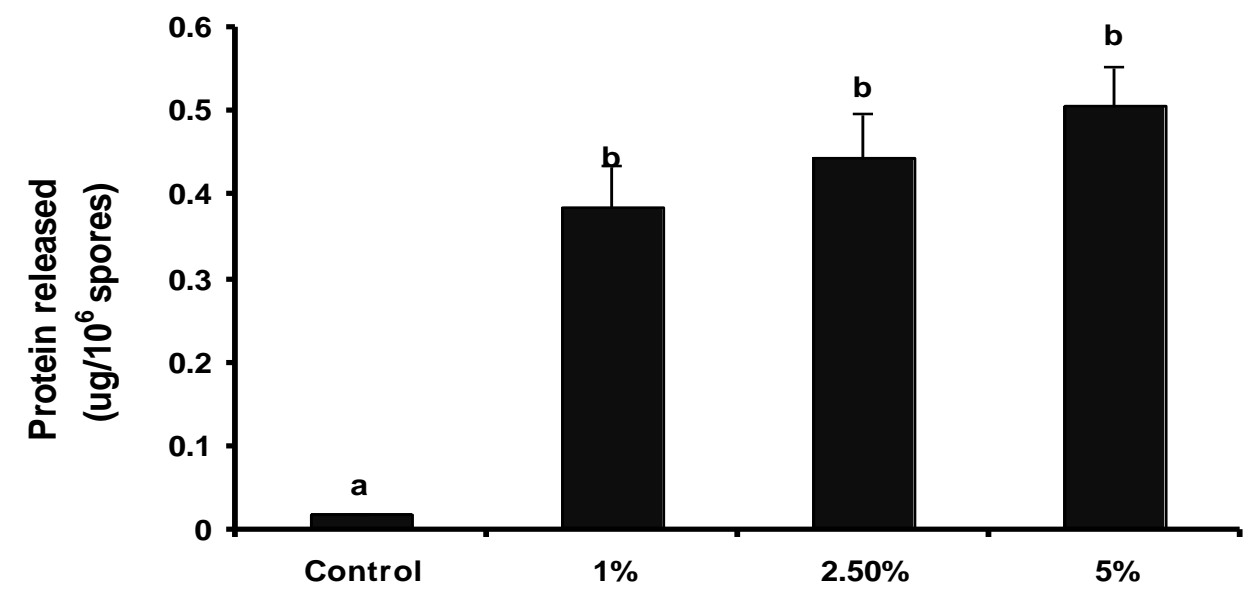

Fig 7:- Effect of bleaching solution on protein loss. Data expressed as mean \pm SD $(n=3)$. Different letters are significant from each other at $\mathrm{P}<0.05$.

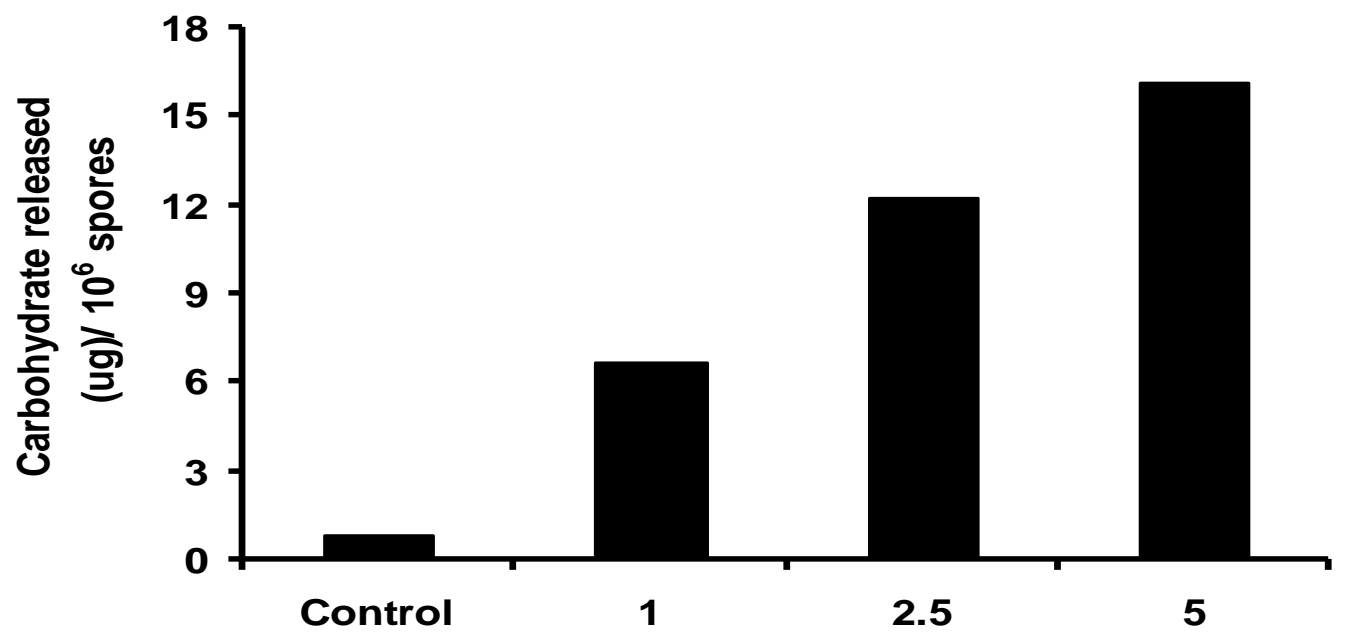

Fig 8:- Effect of bleaching solution on carbohydrates loss 

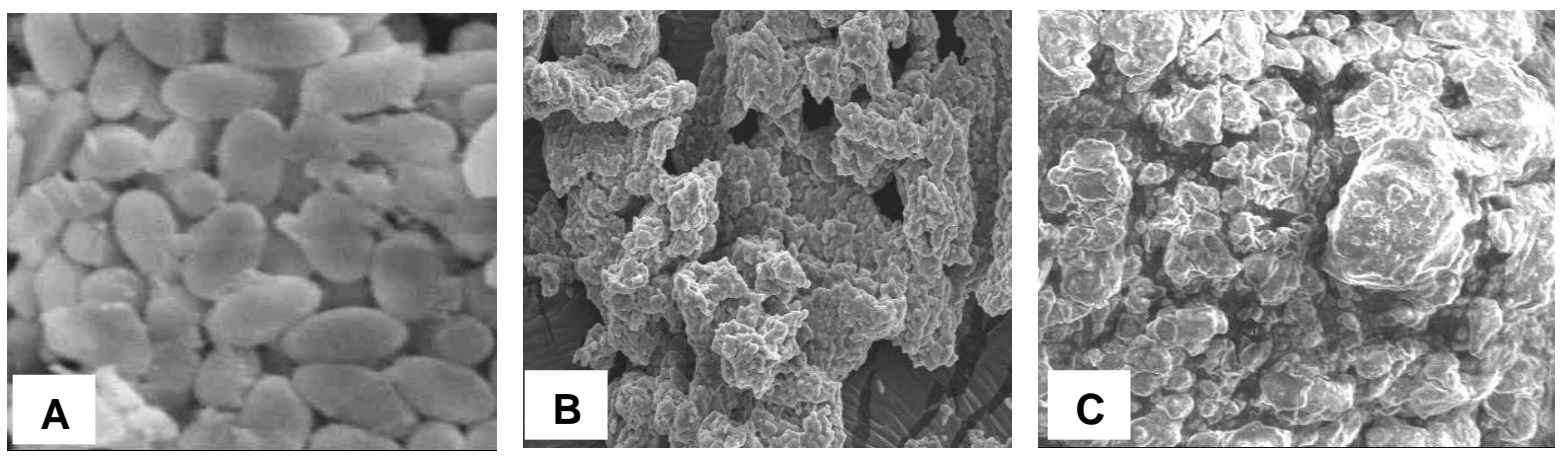

Fig 9:- Scanning electron microscopic images of control (A), 1\% (B) and 5\% (C) treated Noema spores.
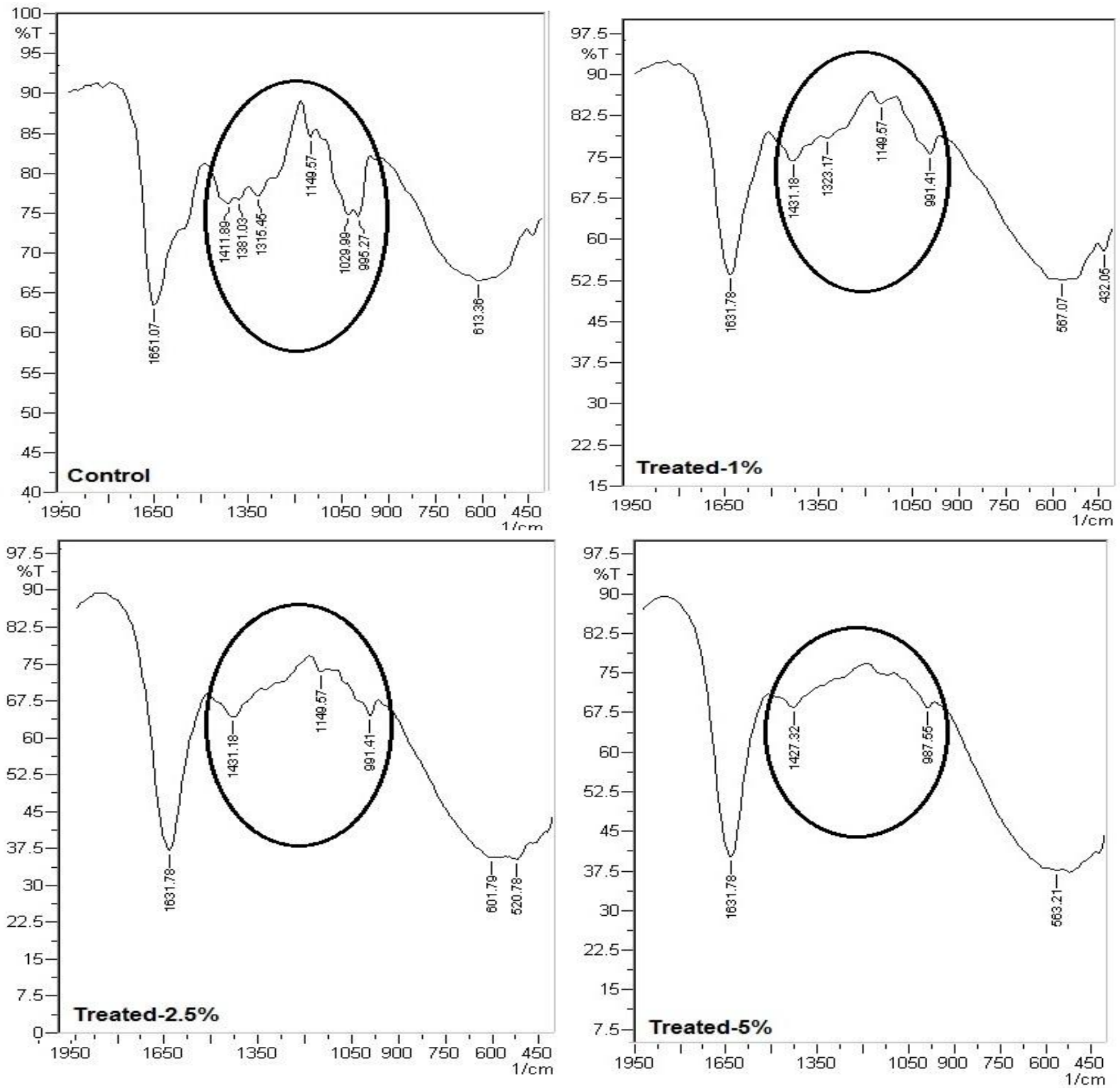

Fig 10:- FTIR Spectra of control and bleaching treated spores. 


\section{Results and Discussion:-}

Bleaching powder solution is an efficient and safe disinfectant, which was recommended by both the World Health Organization and the United States Environmental Protection Administration. It has been used in the fields of disinfection, water purification, food preservation, etc.

Our results show that the $\mathrm{pH}$ of the solutions was $11.83,11.86$ and 11.88 for $1 \%, 2.5 \%$ and 5\% respectively (Fig-1). Similarly the chlorine contents were $1654.8 \pm 102,4379.7 \pm 108$ and $9278.7 \pm 369 \mathrm{mg} /$ lit for $1 \%$, 2.5\% and $5 \%$ bleaching solutions (Fig-2). In the present study time of action for the bleaching solution killing effect on Nosema spores was $1-5 \%$ for $15 \mathrm{~min}$. After treatment, membrane disintegrate was observed after centrifugation (Fig-3). Bleaching solution is an effective disinfectant for Nosema, and very useful in tasar sector. It could be used as an environmental agent or leaf disinfectant, according to its location and application. For further confirmation, to distinguish the effect of inactivation of Nosema spores, AO-PI combined fluorescence staining was adopted to distinguish live cells under the fluorescence microscope (Bank, 1988; Burkart et al., 1992; Dong et al., 1998). Herein, we applied AO-PI combined staining to distinguish between viable and inactivated Nosema spores. The viable spores were bright green in colour, and the inactivated spores were orange-red in colour (Fig-4). This advanced method, used for identifying viable spores, has fast and sensitive. The results indicated gradually clumping if cells from lower to higher doses of treatments (Fig-4)

LPX serves as an indicator of oxidative damage in cells and tissues (Pampanin et al., 2005). An enhanced level of MDA (lipid peroxidation product) in the Nosema spore was observed in response to treatment (Fig-5). Similar to this higher level of LPX was also detected in Nosema spores during $\mathrm{ClO}_{2}$ (Zhengyong et al., 2010). Nosema spores treated with bleaching solution show damage of membrane of lipids from the outer shell and a release in large amount of spore content loss, including proteins (Fig-6 \& 7) and carbohydrates (Fig-8) in a short time. To clarify the structure, high resolution SEM morphology was conducted. The results indicate the high disintegration of membrane damages and clumping of spores in treated samples (Fig-9).

The results of the FTIR spectra gave us the specific absorbance wavelengths of the specific bonds which appeared in the cytosolic fraction. IR spectra measured for spores are usually complex and the peaks are broad due to superposition of contributions from all the bio-molecules present in spore (Fig-10). There are several major absorbance regions in IR spectra were detected in bacterial spores: $1700-1500 \mathrm{~cm}^{-1}$ contains the amide I and II bands of proteins and peptides; $1500-1200 \mathrm{~cm}^{-1}$ is a mixed region of fatty acid bending vibrations, proteins, and phosphatecarrying compounds; $1200-900 \mathrm{~cm}^{-1}$ contains absorption bands of the carbohydrates in microbial cell walls (Helm et al., 1991a,b Naumann, 1991; Naumann et al., 1991; Naumann et al., 1995). In the present case, controls three peaks $\left(1411.89,1381.03\right.$ and 1315.45) were observed at $1500-1200 \mathrm{~cm}^{-1}$ and three $(1149.57,1029.99$ and 995.27$)$ at 1200$900 \mathrm{~cm}^{-1}$ (Fig-10). However, in $1 \%$ treated two peaks (1431.18 and 1323.17) at 1500-1200 $\mathrm{cm}^{-1}$ and another two peaks (1149.57 and 991.41) between 1200-900 $\mathrm{cm}^{-1}$ (Fig-10). Similarly, in $2.5 \%$ treated sample showed one peak (1431.18) between 1500-1200 $\mathrm{cm}^{-1}$ and two peaks (1149.57 and 991.41) between 1200-900 $\mathrm{cm}^{-1}$ (Fig-10). In case of $5 \%$ treated sample showed one peak (1427.32) at 1500-1200 $\mathrm{cm}^{-1}$ and another peak (987.55) at $1200-900 \mathrm{~cm}^{-1}(\mathrm{Fig}-$ 10). There are several interesting peaks that appear on an IR spectrum of spores, and most of them represent functional group vibrations in the main bio-molecular constituents like protein, fatty acids, nucleic acid, and carbohydrates. However, in the present case after bleaching treatment major effects were observed between 1500$900 \mathrm{~cm}^{-1}$. (Fig-10) in Nosema spores, which might be the damaging effect of bleaching solution on membrane structure of spore. Similarly membrane damages and shapes were observed through lipid peroxidation (Fig-5), SEM (Fig-9) and AO-PI staining assay (Fig-4).

Present study further substantiates the utilisation of bleaching powder in tasar culture as effective and efficient agent against the Nosema spores. The potential mechanism Calcium Hypochlorite on Nosema spores was also understood Interestingly, higher level of membrane damage, protein and carbohydrate leakages were observed in Nosema spores treated with bleaching powder solution. Violent changes in the biology of the spores can cause a metabolic disorder and followed by serious damage of the inner structure of the spores (Gao and Huang, 1999). This is the way in which $\mathrm{Cl}_{2}$ acts on spores. It is hypothesized that the high sensitivity of Nosema to bleaching solution is due to the damage of outer shell structure of the spores and releasing the inner cytosolic materials. Our results corroborate with findings of Zhengyong et al., (2010), studied the action of $\mathrm{ClO}_{2}$ on Nosema spores. This is the first report to show mechanism of bleaching solution against Nosema spores, which to be highly-effective disinfectant for tasar industry. 


\section{Acknowledgement:-}

We are thankful to the Head of the Insect Division at CTR\&TI for letting us use the facilities.

\section{References:-}

1. Bank, H.L.(1988): Rapid assessment of islet viability with acridine orange and propidium iodide. In Vitro Cell Dev. Biol., 24 (4): 266-273.

2. Bar-Or, D., Rael, L.T., Lau, E.P., Rao, N.K.R., Thomas, G.W., Winkler, J.V., Yukl, R.L, Kingston, R.G., Curtis, C.G.(2001): An analog of the human albumin N-terminus (Asp-Ala-His-Lys) prevents formation of copper induced reactive oxygen species. Biochem. Biophys. Res. Commun., 284:856-862.

3. Bradford, M.M. (1976): A rapid and snesitive method for quantitaion of microgram quantities of protein utilizing the principle of protein dye binding. Anal. Biochem., 72:248-254.

4. Burkart, V., Koike, T., Brenner, H.H., Kolb, H. (1992): Oxygen radicals generated by the enzyme xanthine oxidase lyses rat pancreatic islet cells in vitro. Diabetologia., 35: 1028-1034.

5. Dong, W., Zhang, H., Wang, Y. (1998): Studies on authenticate method of the quantity of pancreas transplant. J. China Apparatus Transplant., 19 (4): 205-207.

6. Gao, Y. and Huang, K. (1999): Studies on ultrastructure of pathogenic pebrine of silkworm. Sericol. Sin. 25 (3): 163-168.

7. Helm D, Labischinski H, Schallehn G, Naumann D. (1991a): Classification and identification of bacteria by Fourier-transform infrared spectroscopy. J. Gen. Microbiol., 137:69-79.

8. Helm, D., Labischinski, H., Naumann, D.(1991b). Elaboration of a procedure for identification of bacteria using Fourier Transform IR spectral libraries: a stepwise correlation approach. J. Microbiol. Methods., 14:127-142.

9. Jena, K., Pandey, J.P. and Sinha, A.K.(2014): Oxidative Stress and Antioxidant Defences in the Tasar Silkworm Antheraea mylitta D: Challenged with Nosema Species. Int. J. Ind. Entomol., 28(2): 85-91.

10. Jena, K., Pandey, J.P., Priya, A., Kundu, P., Sinha, A.K., Yadav, H. and Sahay, A. (2016): Generation of cytotoxic molecules and oxidative stress in haemolymph of pebrinised tasar silkworm A. Mylitta D. J. Env. Biol.,37:43-48

11. Madhusudhan, K.N., Nungshi-Devi, C. Lokesh, G. Sing, G.P. Sinha, A.K. Kirankumar, K.P. and Prasad, B.C. (2011): Impact of Nosema mylitta (pebrine) infection on the larval parameters, protein concentration and total haemocyte level in Daba ecoraces of Antheraea mylitta D. (tropical tasar silkworm). Microbiol. J., 1: 97-104.

12. Naumann, D., Helm, D. and Labischinski, H. (1991b): Microbiological characterizations by FT-IR spectroscopy. Nature. 351:81-82.

13. Naumann, D., Helm, D., Labischinski, H. and Giesbrecht, K. (1991 a): The characterization of micro-organisms by Fourier Transform Infrared Spectroscopy (FT-IR). Nelson WH ed. Modern Techniques for Rapid Microbiological Analysis. VCH. New York, NY. 43-96

14. Naumann, D., Keller, S., Helm, D., Schultz, C. and Schrader, B. (1995): FT-IR Spectroscopy and FT-Raman Spectroscopy are powerful analytical tools for the non-invasive characterization of intact microbial cells. J. Mol. Struct. 347:399-406.

15. Pampanin, D.M., Camus, L., Gomiero, A., Marangon, I., Volpato, E. and Nasci, C. (2005). Susceptibility to oxidative stress of mussels (Mytilus galloprovinicialis) in the Venice lagoon (Italy). Mar Pollut Bull., 50(12):1548-57.

16. Rath, S.S., Prasad, B.C. and Sinha, B.R. (2003): Food utilization efficiency in fifth instar larvae of Antheraea mylitta (Lepidoptera:Saturniidae) infected with Nosema sp. and its effect on reproductive potential and silk production. J. Invertebr. Pathol., 83:1-9.

17. Renuka, G. and Shamitha, G. (2012): Studies on the excretory products of pebrine infected tasar silkworm, Antheraea mylitta Drury (Daba BV). Int. J. Pharm. Bio. Sci., 3: 1054-1062.

18. Zhengyong, W., Fupin, L., Jianrong, L., Wenchu, L., Yangsheng, Z., Peichan, T. and Ziran, H. (2010): Inactivation and mechanisms of chlorine dioxide on Nosema bombycis. J. Invert. Pathol., 104:134-139. 